\title{
An Innovative Seismic Protection System for Conventional RC Buildings
}

\author{
Zekirija Idrizi $^{1}$ and Isak Idrizi ${ }^{2}$ \\ 1. Faculty of Civil Engineering and Architecture, Hasan Prishtina University, Prishinë 10000, Kosova; \\ 2. Faculty of Civil Engineering and Architecture, Mother Teresa University, Shkup 1000, Macedonia
}

\begin{abstract}
As capacity design philosophy suggests, the best way to achieve a safe seismic response of multistory buildings, under strong earthquakes, is to uniformly spread the inelastic deformation demands throughout the building structure. Unfortunately, this type of mechanism is difficult to be reached due to the abundant presence of infill wall panels on buildings, which under strong earthquakes show severe cracks and strength degradations, thus complicating the seismic response of buildings. In order to avoid these brittle mechanisms of failure, studies were made toward development of new seismic protection system which would completely protect the infill walls from any cracks and strength degradation manifestations and simultaneously improve the seismic response of the entire structure. Utilization of the "IDRIZI" seismic protection system, would greatly contribute to many important aspects, like the increase of structural seismic performance, drastic reduction of damages under strong earthquake events and avoiding any unpredictable local failure mechanisms on buildings.
\end{abstract}

Key words: Infill walls, IDRIZI seismic protection system, passive control, friction device.

\section{General Introduction}

Based on many collected data and in-situ observations from past earthquakes, it was concluded that prior to failure of structural members almost all the time significant damage occurs to infill wall panels in buildings (Fig. 1). The reason for this phenomenon, as it is already known, is due to the mechanical properties of infill wall panels vastly used today, which are characterized with high brittleness and very low ductility levels. Because of these features, the positive effect of infill walls on the seismic response of buildings can be taken into account only in the linear stage of structural behavior since there are no plastic deformations in the building. However, under stronger earthquake events, buildings are subjected to larger deformations followed up with noticeable cracks and strength degradation of infill wall panels. This stage of structural response can be very dangerous for RC

Corresponding author: Isak Idrizi, doctor of science, assistant professor; research fields: earthquake engineering and structural engineering. E-mail: isak.idrizi@unt.edu.mk, isak_idrizi@hotmail.com. (reinforced concrete) buildings, since a sudden failure of infill walls would impose unwanted local failures to RC structural members resulting to a severe degradation of RC member elements followed by a total structural collapse.

Considering that infill wall panels are present almost in every building, with more than $80 \%$ of participation percentage on building frames, it is believed that a proper and controlled utilization of infill wall panels as components of the lateral resisting system of buildings would greatly affect the ultimate seismic performance of buildings. In the search for improvement of seismic performance of RC buildings with infill walls, a new seismic protection system for RC buildings has been conceptualized, namely "IDRIZI" seismic protection system, which in general is expected to show noticeable increase on overall structural ductility.

The study focus of this paper is to present the most characteristic results that show the level of seismic response improvement of buildings with utilized "IDRIZI" seismic devices, while detailed studies on the componential level of IDRIZI seismic protection 


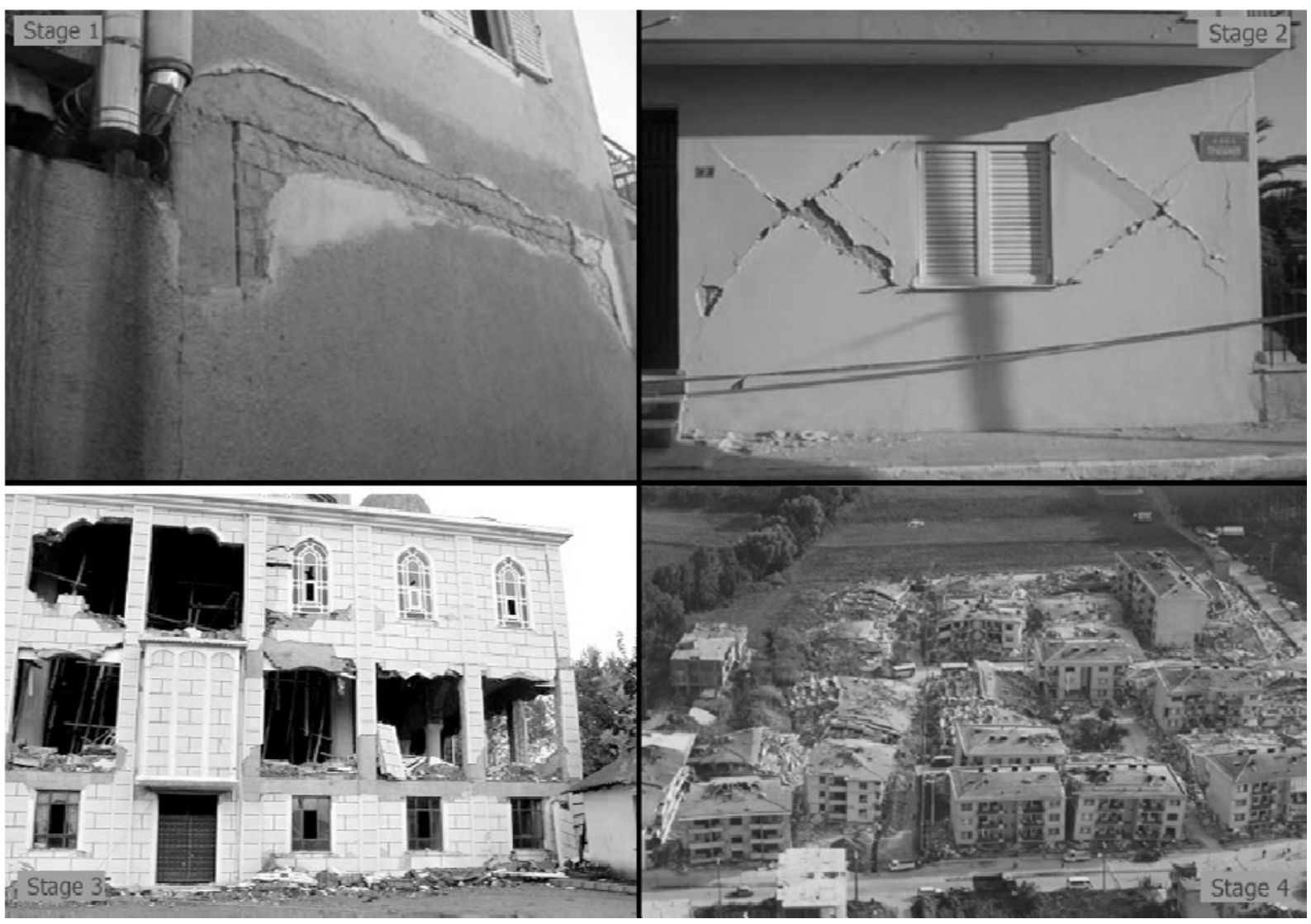

Fig. 1 Stages of infill wall failure on RC structures (from small cracks up till total structural collapse).

system, i.e., studies on the performance of "IDRIZI" devices are currently under development, thus are not demonstrated herein.

\section{The Concept of “IDRIZI" Seismic Protection System}

The basic idea of the so-called "IDRIZI" seismic protection system is to effectively engage the shear capacity of infill walls in order to maximize the shear resisting capacity of the structure subjected to seismic loads, while simultaneously avoiding manifestation of any strength degradations on infill wall panels [1].

This effect is achieved through introduction of special seismic links, i.e., "IDRIZI" devices which serve as contact points between the infill wall panels and the primary lateral resisting system of the structure, respectively beams or slabs (Fig. 2). After the placement of IDRIZI devices at characteristic locations between the infill wall panels and the beams of the structural frames, a vertical pre-compression is generated in both the infill wall panel and the horizontal beam through the IDRIZI devices. Through this pre-compression force, an additional increase in the shear resistance of infill wall panels is achieved and, more importantly, a frictional force is generated at the contact surface between the IDRIZI device and the beam. This friction force dissipates the kinetic energy transmitted to the structure from ground vibrations, thus acting as the first line of defense of the structure from earthquake events. Experimental investigations have shown that the IDRIZI devices show very stable "perfectly stiff/perfectly plastic" hysteretic behavior under many cycles of lateral oscillations of the frame (Fig. 2) [1-4].

As can be observed from the experimental investigations (Fig. 2), the IDRIZI seismic protection system is very effective toward protecting the structural integrity of infill walls (with or without doors 

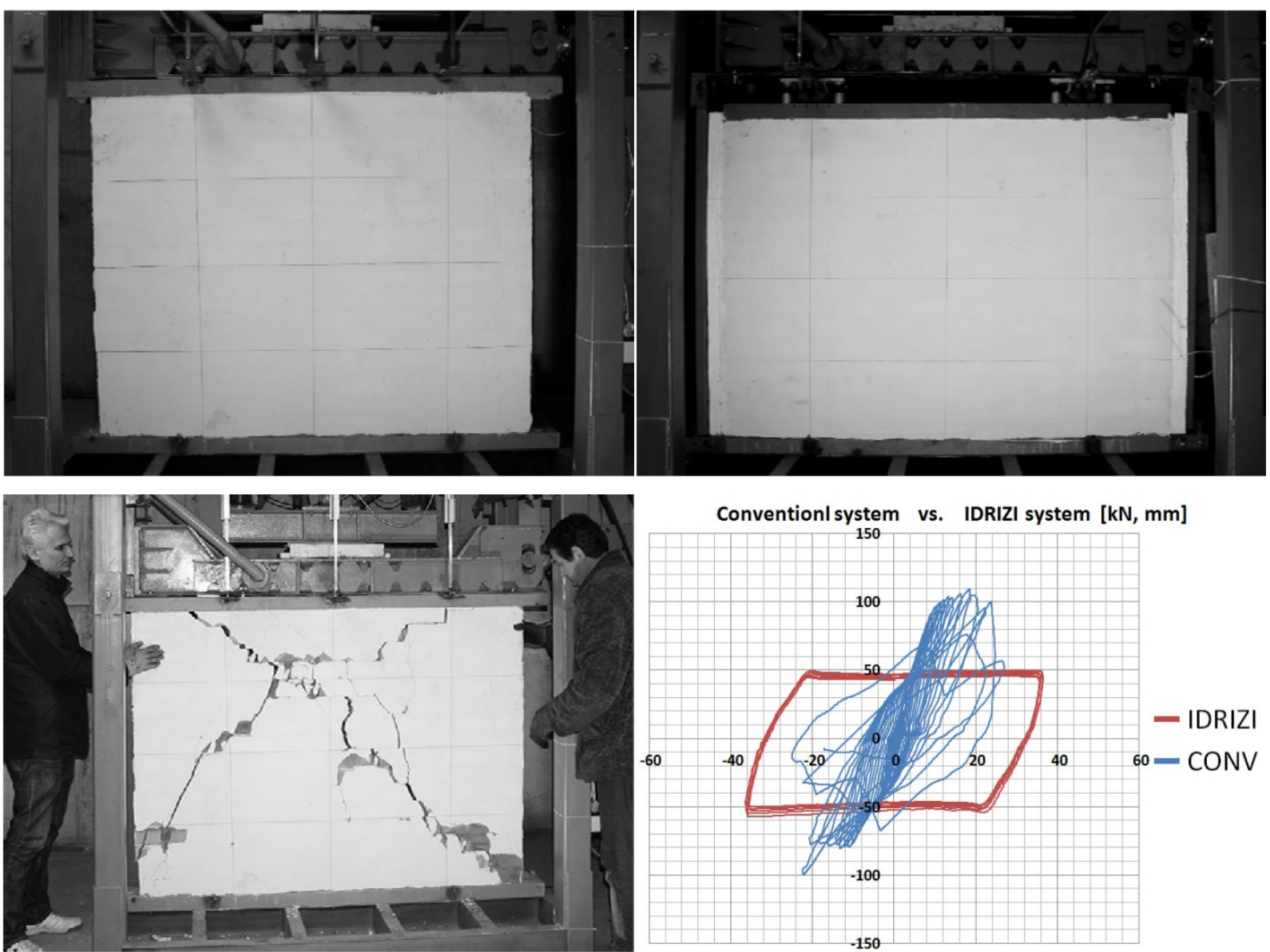

Fig. 2 Conventional vs. IDRIZI system—experimental investigations.

and windows), by controlling the maximum level of shear forces resisted through infill walls.

Ultimately, the function of IDRIZI devices is based on friction. By utilization of IDRIZI device on characteristic location of building frames, an "IDRIZI" seismic protection system is achieved which not only protects the nonstructural walls on buildings from cracks and damages but it also facilitates the dissipation of earthquake energy, increases the global structural damping and facilitates the development of higher ductility levels on structural bearing elements.

\section{Mathematical Modeling}

In order to demonstrate the seismic response improvements of buildings utilized with IDRIZI seismic control devices, there have been generated three variations of mathematical models representative for the 7-storey building (Fig. 3), using SAP2000 v.14 program.

The first model (CONV-A, Fig. 3-left), represents a dual structural type of a 7-storey RC building without consideration of infill walls panels. In the second model (CONV-B, Fig. 3-middle) are also modeled the conventional infill walls consisted of hollow clay brick units, while the utilization of "IDRIZI" devices on RC buildings with infill walls is represented by the third model (HD-A, Fig. 3-right).

All material properties of structural and nonstructural elements and loading characteristics remain identical to all of the three models. In consideration to the load analysis, it can be outlined the overall gravitational load (self weight, dead load and live load) weighting about 6,000 t. The material used for all structural members (columns, walls, beams and slabs) is reinforced concrete with concrete class C30/35 and steel class S400. In addition, various 


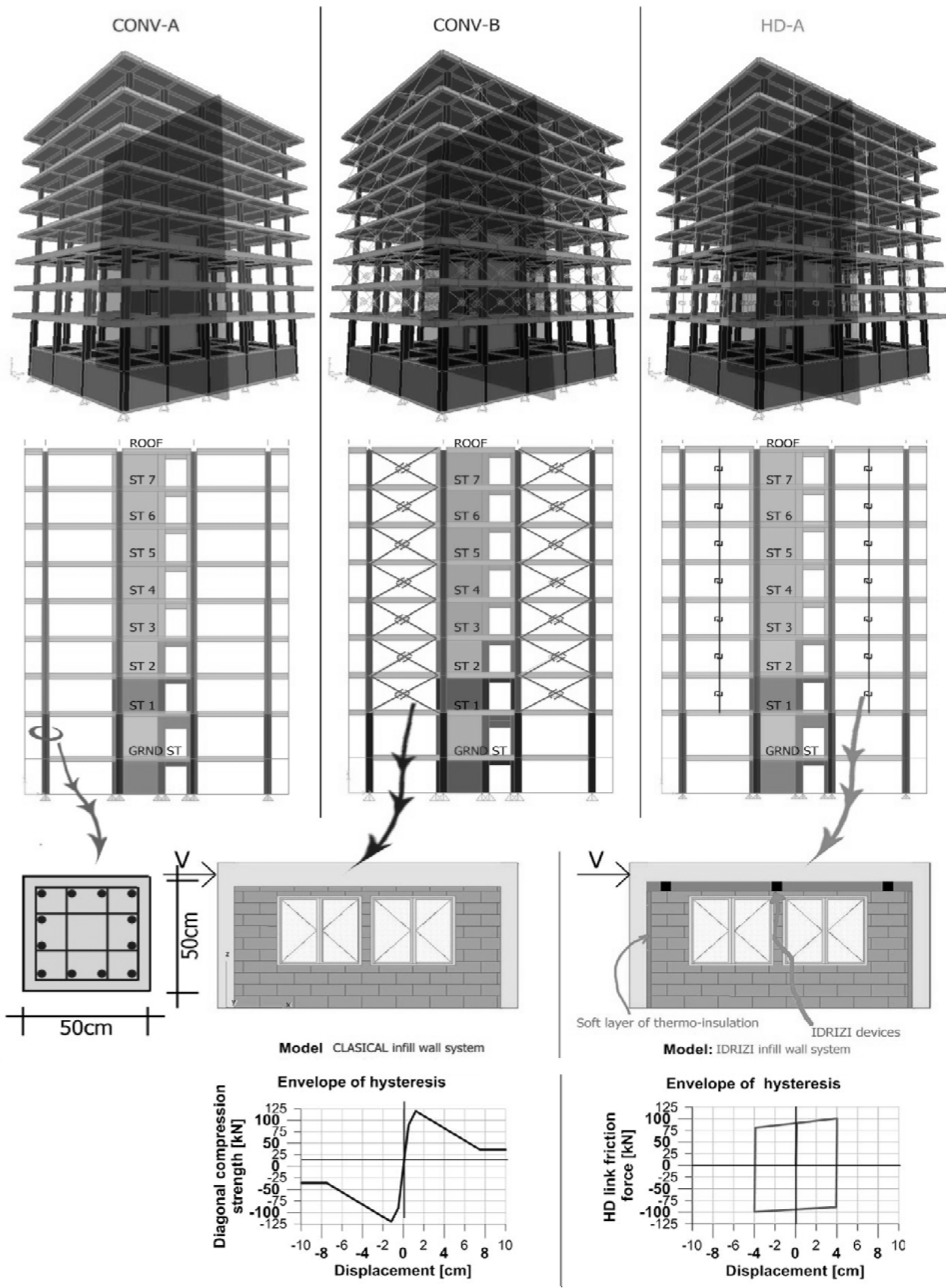

Fig. 3 3D mathematical models representative for a 7-storey building. 
nonlinearity considerations of structural and nonstructural elements have been taken into consideration and have been kept consistent throughout the modeling process of all three models shown in Fig. 3.

\section{Seismic Response Verification of Buildings with "IDRIZI" Wall System}

The seismic response verification of all three building models is done using direct integration time-history analysis. Direct-integration time-history analysis is the ultimate FEM (finite element method) based technique which takes into account the full nonlinearity features of all elements constituting the mathematical models, and it requires significantly more calculation time to obtain results. While not being the most efficient tool in terms of time duration of calculations, it certainly is the most effective tool in analysis and detection of even the most complicated dynamic behaviors of structural models [4].

Under nonlinear direct-integration time-history analysis, all three models were subjected to the Izmit earthquake accelerations acting on all three orthogonal directions $\mathrm{X}, \mathrm{Y}$ and $\mathrm{Z}$. In addition, all three models were the considered with all nonlinear features described earlier in Sections 2 and 3. For consideration of the IDRIZI devices, it was used the plastic (Bouc-Wen) hysteretic model available in SAP2000 computer program.

Some of the most representative results obtained from these analysis, are presented in Figs. 4-7. These figures help to describe the dynamic response of all three models.

In order to get a basic understanding about the behavior of structures under free vibrations, in this paper are presented the first three vibration modes and vibration periods for all three models, generated from modal analysis. In Fig. 4 are given the first 3 modal periods of vibration for all three study case models CONV-A, CONV-B and HD-B. This figure shows the stiffening effect increasing from CONV-A to HD-A model. This effect, obviously, reflects the consideration of infill walls in CONV-B and HD-A models.

In Fig. 5 are shown the time-history responses of storey displacements of all three models, in $\mathrm{X}$ direction. In general, all models show similar responses with gradual reduction of story displacement levels. Thus top lateral displacements about the $\mathrm{X}$ direction are reduced from $17.5 \mathrm{~cm}$ for CONV-A model down to $14 \mathrm{~cm}$ for HD-A model. In addition, the envelope curves of lateral displacements along stories of all three models (Fig. 7), show the reduction effect of lateral displacements on the $\mathrm{Y}$ direction as well.

The differences between the conventional and IDRIZI structural system are obvious and quite interesting. According to Fig. 6, infill wall panels of the conventional system (Fig. 7-left) show excessive nonlinear behavior with strength degradation at the bottom stories while through the upper stories they get

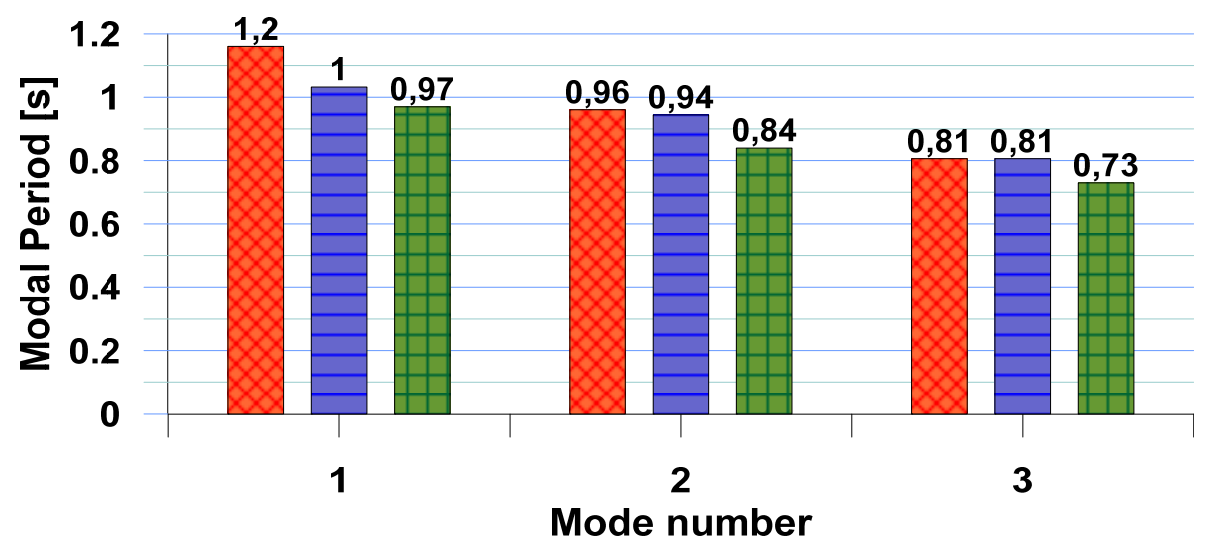

Fig. 4 Modal analysis results for all three models. 


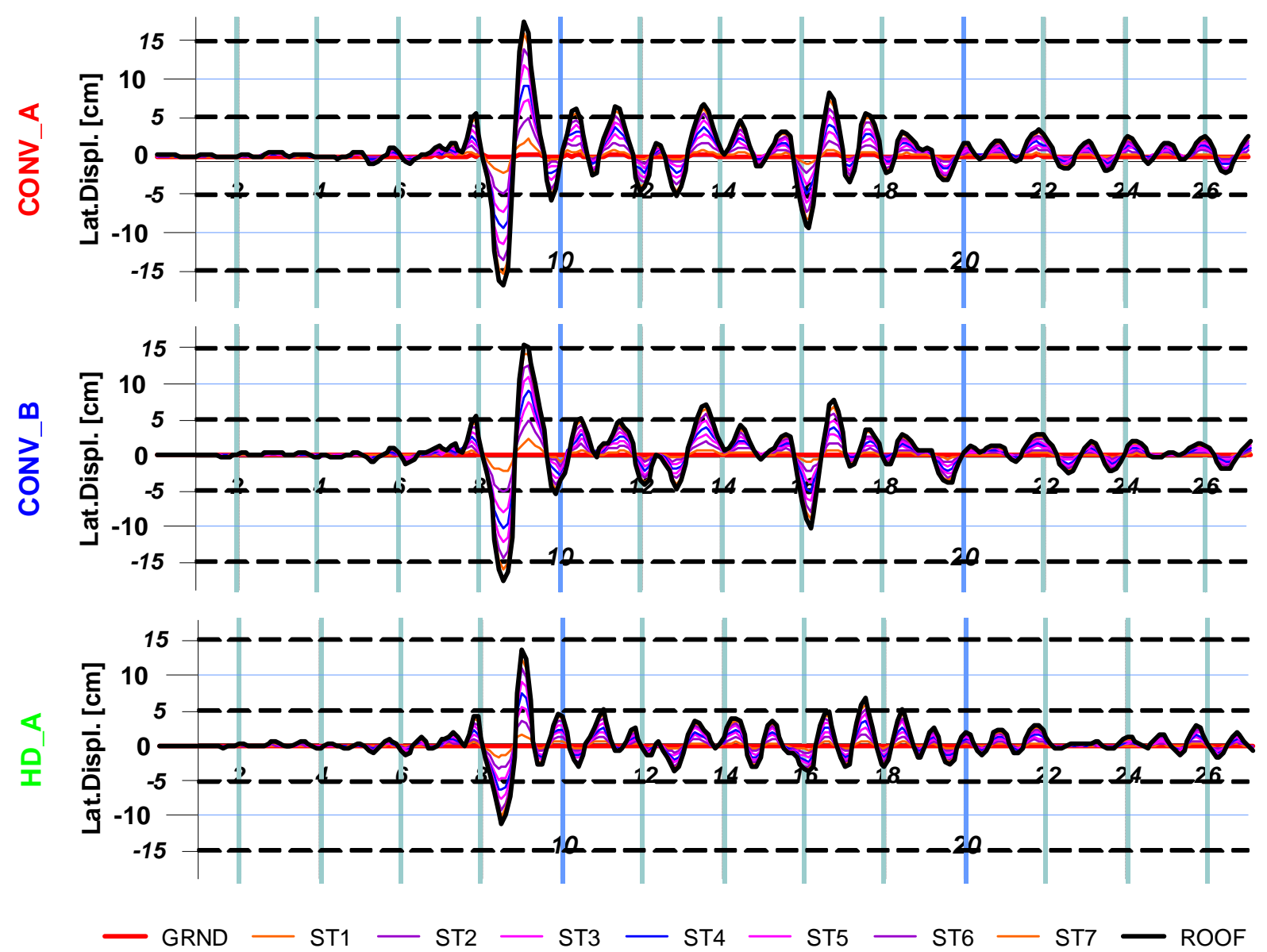

Fig. 5 Story displacement time-history of all three models under Izmit earthquake, X direction.

reduced down to almost no nonlinearity at all. Moreover, the conventional infill wall panels show non-symmetrical hysteretic behavior throughout all stories of the building.

Contrary to the conventional system, the IDRIZI system (Fig. 7-right), demonstrates a quite stable dynamic response throughout the entire height of the HD-A model. There is not evident any strength degradation. The hysteretic response, although stable, it is shifted to the left of the balance line which after earthquake event automatically returns back to the initial position along with all other structural elements of the building.

Comparing the displacement responses of all three models (CONV, CONV-B and HD-A) in Fig. 6, the first thing to be observed is that all three models demonstrate similar response pattern, following the logic of capacity design philosophy, i.e., all stories are proportionally activated for energy dissipation of seismic forces, especially the first three stories (ST1 to ST3). Moreover, due to the lack of infill walls on the ground floor, and because of the higher story height, the story displacements and inter-story drifts of the ground story are somewhat more amplified. The phenomenon of response amplifications usually on the ground stories of multi-storey buildings is widely known as "soft-story" phenomena. Despite the soft-story effect, all three models prove to have sufficient strength capacities to successfully resist these amplification effects on the ground story. According to Fig. 5, all three models respond appropriately throughout the time duration of Izmit earthquake without any permanent displacements, i.e., no offset from the balance line is observed in the time/history graphs.

In Fig. 7 are presented the envelope curves of lateral 

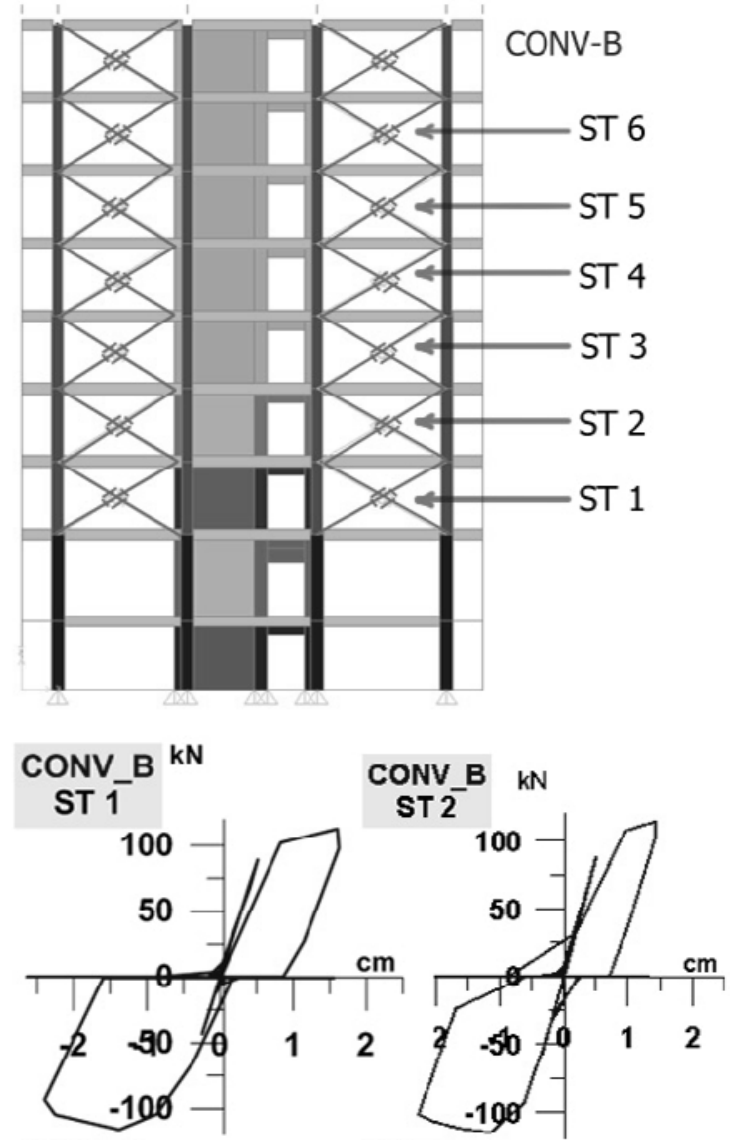

CONV_B kN

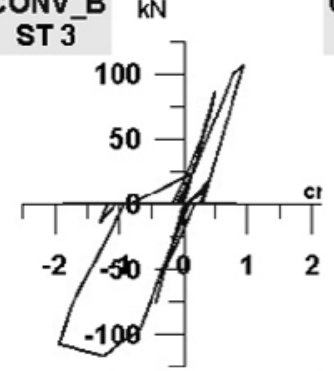

ST $^{-} \mathrm{kN}$
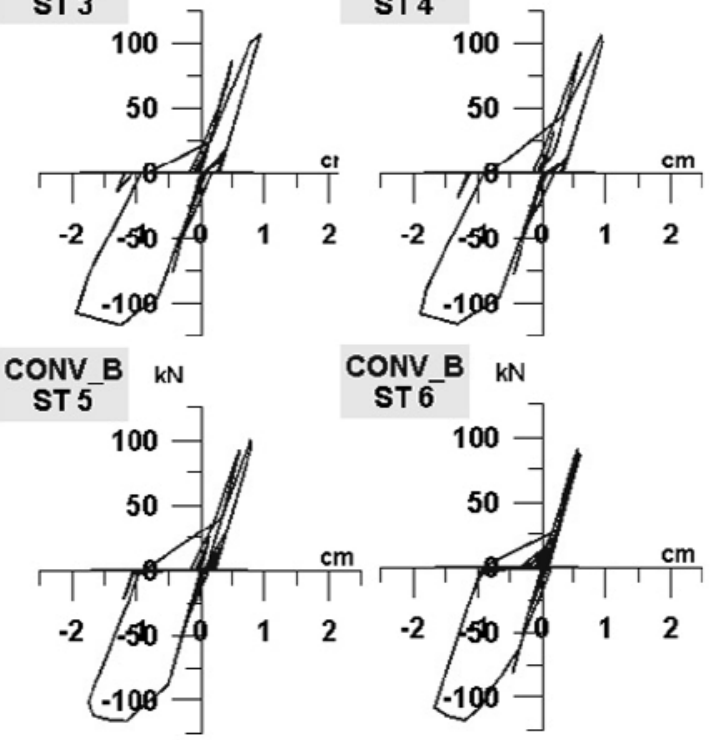
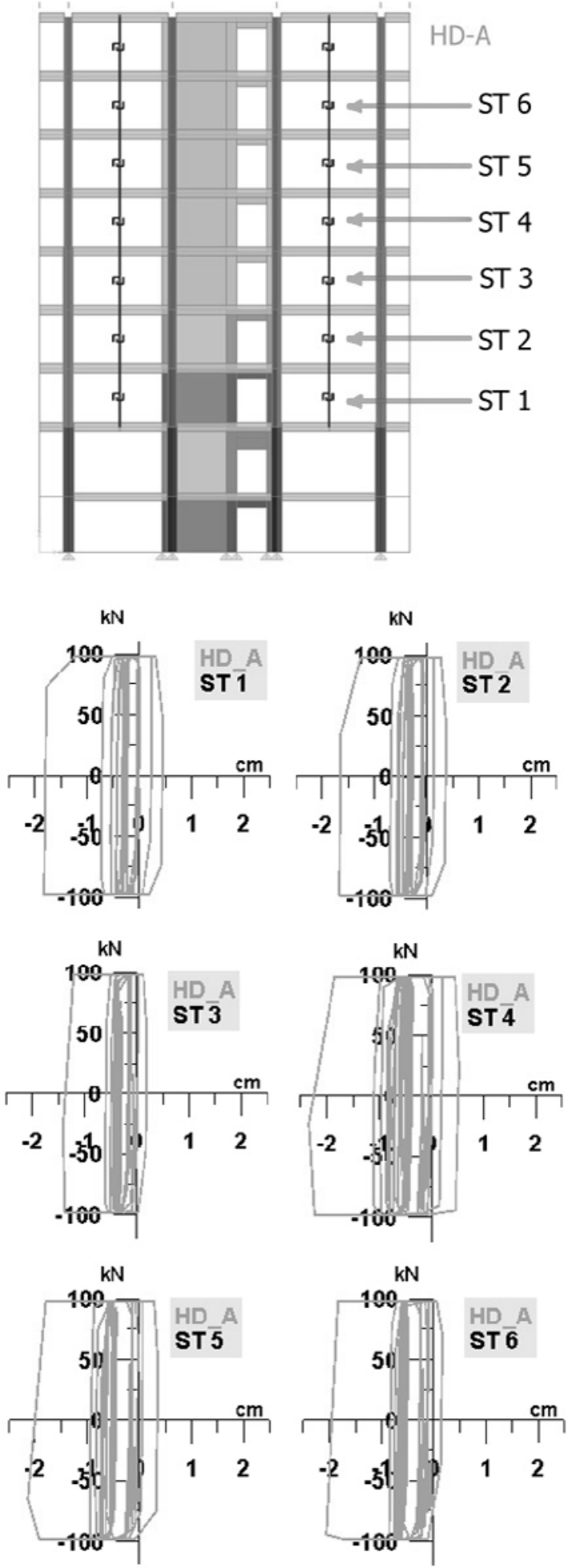

Fig. 6 Hysteretic behavior of infill panel element, under Izmit earthquake-X direction. 


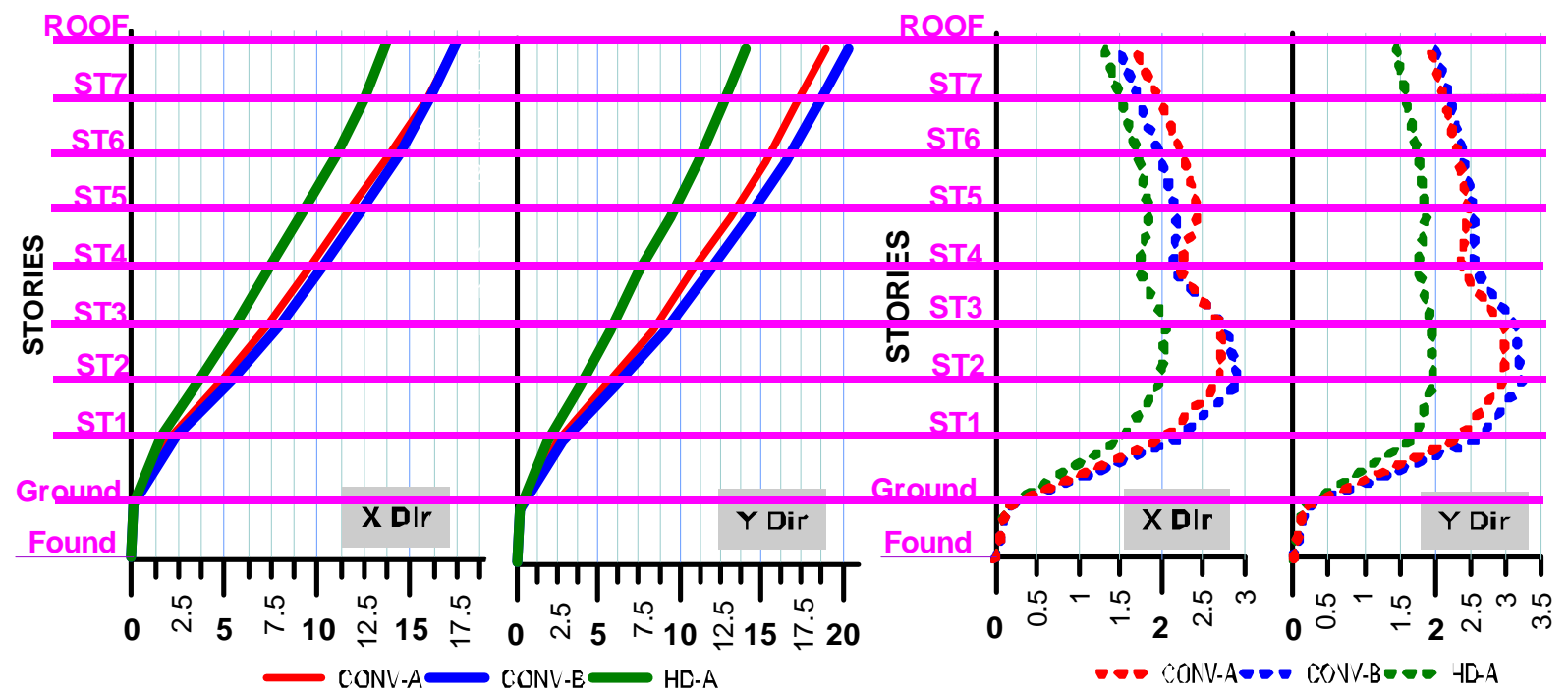

Envelope of story displacements [cm]

Fig. 7 Envelopes of story displacements and drifts in $\mathrm{X}$ and $\mathrm{Y}$ dir, under Izmit earthquake.

displacements (left) and storey-drifts (right) along the height of all three models. Lateral storey displacement envelopes (Fig. 7-left) show once again the slight decrease of lateral displacements on the ground story of HD-A model in respect to both CONV-A and CONV-B models. Moreover, the envelopes of lateral storey drifts (Fig. 7-right) better demonstrate that all the stories respond proportionally to the seismic forces acting on the building. One more thing that should be observed is that the stable dynamic response of all three models is greatly controlled by the $\mathrm{RC}$ core wall located at the center of all three models. Actually, due to this RC core wall, which is much more stiffer and stronger in respect to infill walls, the models are not noticeably affected by the upgrading of conventional infill walls with HD infill wall panel system. Although, the improvement effects in terms of lateral building strength is expected to be much higher on "frame" types of structures.

\section{Conclusions}

Considering the brittle nature of infill wall panels and the relatively low lateral strength capacities, they are generally applied for fulfilling the architectural requirements and not to serve as load bearing or lateral resisting systems. By this paper, it has been endeavoured to present an innovative idea of making minor adjustment on conventional infill walls in order to improve the structural response of conventionally designed buildings. According to this study, by upgrading the conventional structural system to IDRIZI system through introduction of IDRIZI deviceson characteristic locations of building frames, no cracks or strength degradation of infill walls occur anywhere. Consequently, any unpredictable local failure mechanisms on structural elements $[5,6]$ due to concentrated stress releases for infill walls failures are completely avoided. In addition, depending on the structural type of buildings, there are expected notable improvements on structural strength and structural ductility levels.

\section{References}

[1] Idrizi, I., Dorka, U. E., and Idrizi, Z. 2012. "Application of HYDE Structural Control System for RC Buildings.” Presented at 15th World Conference on Earthquake Engineering, 15WCEE 2012, Lisbon, Portugal.

[2] Idrizi, I., Ristic, D., and Idrizi, Z. 2012. "Estimation of Seismic Response Improvements on RC Buildings with Innovative 'HD' Infill Wall Panels.” Presented at 15th World Conference on Earthquake Engineering, 15WCEE 2012, Lisbon, Portugal.

[3] Idrizi, I., Ristic, D., and Idrizi, Z. 2010. "Importance of $\mathrm{P} /$ Delta Effect in Inelastic Behavior of 9 Story RC Frame Structures with Consideration of Infill Walls.” Presented at 14th European Conference on Earthquake Engineering, 
Macedonia.

[4] Idrizi, I. 2009. "Effect of Infill Walls on Seismic Response of RC Buildings.” Master thesis, University SS. Cyril and Methodius, Institute of Earthquake Engineering and Engineering Seismology, IEEES, Macedonia.

[5] Idrizi, I., Ristic, D., and Idrizi, Z. 2009. "Study of Qualitative Effects of Dfferent Infill Types on Seismic Response Modification of RC Buildings.” Presented at
Comutation Methods in Structural Dynamics and Earthquake Engineering, COMDYN 2009, Rhodes, Greece.

[6] Idrizi, I., Idrizi, Z., Idrizi, I., Idrizi, Sh., and Idrizi, N. 2009. "Effect of Infill Walls in Structural Response of RC Buildings.” Presented at 5th International Structural Engineering and Construction Conference, ISEC-5 2009, Las Vegas, USA. 